\title{
GÊNEROS DISCURSIVOS NA AULA DE PORTUGUÊS: A (NÃO) FORMAÇÃO DO ALUNO PRODUTOR DE ENUNCIADOS
}

\author{
DISCURSIVE GENRES IN PORTUGUESE CLASSES: STUDENT'S DEVELOPMENT AS WRITTEN TEXT- \\ STATEMENTS PRODUCER
}

\author{
GÉNEROS DISCURSIVOS EN CLASE DEPORTUGUÉS: LA (NO) FORMACIÓN DEL ALUMNO PRODUCTOR \\ DE ENUNCIADOS
}

Josa Coelho Irigoite*

Universidade Federal de Santa Catarina - UFSC, Florianópolis, BR

\begin{abstract}
RESUMO: Este artigo traz como tema a aula de Português, com foco em fatores que comprometem a formação dos alunos como produtores de textos-enunciado escritos em diferentes gêneros discursivos. A pesquisa se constitui em uma pesquisa-ação, com ancoragem etnográfica, cuja geração de dados partiu da inserção em uma escola estadual situada no município de São José, nas aulas de Português de uma turma do $1^{\circ}$ ano do Ensino Médio, que tiveram como foco norteador o gênero crônica. A análise dos textos produzidos baseou-se em dois grandes eixos teóricos: a ancoragem sociointeracionista vigotskiana e o conceito bakhtiniano de gêneros do discurso. Os resultados mostram a não apropriação do gênero crônica por parte desses alunos, refletida nos textos produzidos, o que pode sinalizar para o fato de que as escolas não têm formado alunos produtores de textos-enunciado.

PALAVRAS-CHAVE: aula de português; crônica; gêneros do discurso; produção textual.
\end{abstract}

ABSTRACT: The theme of this article is the Portuguese class, focusing on factors that compromise students' formation as written text-statements producers in different discursive genres. The data was generated through an action research, with an ethnographic anchor, carried out in the Portuguese classes of a 1st-year high school class, in a state school situated in São José, Santa Catarina. The chronical genre was the main focus of the research. The analysis of the texts produced was done according to two main theoretical axes: Vigotski's social-interactionist anchoring and Bakhtin's concept of discursive genres. The results show the lack of appropriation of the chronicle genre by these students as reflected in the texts produced by them. This may point to the fact that the school have not been preparing students to be producers of written texts-statements.

KEYWORDS: Portuguese class; chronicle; discursive genre; text production.

RESUMEN: Este artículo trae como tema el clase de Portugués, centrándose en factores que comprometen la formación de los alumnos como productores de textos-enunciado escritos en diferentes géneros discursivos. La pesquisa se constituye en una pesquisa-acción, con ancoraje etnográfica, cuya generación de datos partió de la inserción en una escuela provincial situada en la ciudad de São José, en clases de Portugués de una clase de $1^{\circ}$ año de Escuela Secundaria, se han centrado en el género crónica. El análisis de los textos producidos se basó en dos grandes ejes teóricos: el anclaje sociointeraccionista vigotskiana y el concepto bakhtiniano de géneros del discurso. Los resultados muestran la no apropiación del género crónica por parte de esos alumnos, que se refleja en los textos producidos, lo que puede señalar para el hecho de que las escuelas no han formado alumnos productores de textos-enunciado.

PALABRAS-CLAVE: clase de Portugués; crónica; géneros del discurso; producción textual.

\section{INTRODUÇÃO}

A importância que a escrita tem e as funções que desempenha atualmente na vida de comunidades distintas é objeto de estudo na Linguística Aplicada - teorizações sobre letramento são exemplos disso - e tem profundas relações com o recorte deste artigo. Em se tratando de ambientações crescentemente mais marcadas pela presença dessa modalidade da língua, como os contextos urbanos perpassados pelas diferentes tecnologias, possivelmente nunca os homens que vivem nessas ambientações estiveram tão rodeados por material escrito e possivelmente, ainda, nunca as demandas por dominar essa modalidade em suas diferentes configurações tenham se estabelecido de igual modo. Há, nesses contextos, muitos livros impressos, inúmeros jornais e revistas, panfletos, cartazes publicitários, manuais explicativos. Há, ainda, os diversos gêneros materializados em suportes virtuais na internet. Parece certo que, na cultura ocidental das grandes metrópoles, a escrita está presente de modo recorrente (FISCHER, 2006). 
Paradoxalmente, porém, em determinados contextos da geografia nacional, parece não haver leitores e produtores de textos para muitos gêneros discursivos que instituem essa profusão de textos-enunciado. Essa é uma discussão que tem se consolidado nas últimas décadas e que geralmente se volta para a escola, instituição historicamente concebida como responsável pela formação do leitor e produtor de textos - em tese, a principal agência de letramento (KLEIMAN, 2001 [1995]) -, processo implicado na formação do cidadão, dadas as relações historicamente construídas entre cidadania, escolarização e erudição (GRAFF, 1994). Assim, é válido questionar em relação à produção textual (foco deste artigo): O que e para que nossos alunos escrevem em nossas sociedades grafocêntricas ${ }^{1}$ contemporâneas? Estamos formando produtores de textos-enunciado em nossa ação escolar? Mas o que significa formar produtores de textos-enunciado? Dados de indicadores como o Indicador Nacional de Alfabetismo Funcional (Inaf) e testes internacionais aplicados pelo Programa de Avaliação Internacional de Estudantes (Pisa) sinalizam para um baixo rendimento de brasileiros de diferentes regiões do país nos usos da modalidade escrita. Olhares mais pontuais também tendem a confirmar essa preocupação que emerge dos dados dos indicadores massivos: são os trabalhos de estudiosos que levantaram problemas da aula de Português nas últimas décadas - Geraldi (1997 [1991]), Kleiman (2001[1989]), Britto (1997), Antunes (2003), Batista (1997), Zilberman (1993), apenas para citar alguns deles. Esses estudos nos fazem pensar mais detidamente sobre nosso papel na ressignificação das práticas de escrita de nossos alunos, sobretudo nos entornos menos privilegiados socioeconomicamente.

Pensando nesses questionamentos, este artigo traz um recorte de uma pesquisa-ação realizada em uma turma de $1^{\circ}$ ano do Ensino Médio de uma escola estadual situada no município de São José, que incluiu observação participante de treze aulas de Português da professora local, com geração de notas de campo, e minha ação protagonista ao longo de vinte e quatro aulas. A inserção nessa escola, assim, nasceu da vontade de construir inteligibilidades para o que parece ser um problema linguístico socialmente relevante (MOITA LOPES, 2006): potenciais dificuldades para ressignificar práticas de escrita de alunos inseridos em ambientações com baixos níveis de escolarização e socioeconomicamente desprivilegiadas. Todas as aulas pesquisadas tiveram como foco norteador o gênero crônica, encaminhamento feito pelas Olimpíadas de Português $^{2}$, concurso do qual a turma em questão iria participar no semestre seguinte. A metodologia desenvolvida no período de intervenção e a análise dos textos produzidos pelos alunos tiveram como bases teórico-epistemológicas dois grandes eixos: o conceito de gêneros do discurso, com base no pensamento do Círculo de Bakhtins, e o sociointeracionismo de Vigotski.

Este artigo traz alguns principais pressupostos de cada teoria adotada e suas respectivas contribuições para o ensino e aprendizagem de língua materna. Em seguida, apresenta-se uma análise das atividades de produção textual tal qual foi vivenciada ao longo da pesquisa, tanto nas aulas observadas como nas aulas ministradas. Especificidades das produções textuais dos alunos, que os distanciam de uma performance globalmente esperada, mereceram especial atenção, que será relatada neste artigo.

\section{A ANCORAgeM TEÓRICA dA PRÁtica PEDAgógicA: PENSAMENTo DE BAKHTIN E DE VIGOTSKI COMO EIXOS}

É inquestionável a importância que os dois eixos teóricos que embasaram esta pesquisa possuem hoje no âmbito escolar, sobretudo o conceito de gêneros do discurso. Basta olharmos livros didáticos atuais para conferirmos a enorme variedade de textos-enunciado em múltiplos gêneros discursivos. Documentos oficiais como os PCNs de Língua Portuguesa (BRASIL, 1998) ancoram-se nesses ideários, que também

\footnotetext{
1 Entendo por grafocêntricas as sociedades em que a escrita e a leitura estão presentes, ou seja, as pessoas que circulam por tais sociedades têm contato direto com a modalidade escrita, quer dominem o código ou não. Segundo Fischer (2006, p. 280), “[...] a multiplicação, diversificação, proliferação e aceleração do material escrito caracterizam a atual 'pandemia de informações. E como se trata de um fenômeno fundamentado na leitura, são as estratégias nela baseadas que compõem a reação atual.”. Entendo que a leitura, assim, nessas sociedades que exaltam a palavra escrita, reflete - tanto quanto suscita - transformações na organização das interações humanas.

2 A Olimpíada de Língua Portuguesa - escrevendo o futuro é uma iniciativa do Ministério da Educação (MEC) e da Fundação Itaú Social (FIS), com a coordenação técnica do Centro de Estudos e Pesquisas em Educação, Cultura e Ação Comunitária (Cenpec). Trata-se de um programa de caráter bienal e contínuo, que visa proporcionar oportunidades de formação aos professores da rede pública. Em anos ímpares, atende agentes educacionais: técnicos de secretarias de educação que atuam como formadores, diretores, professores. Em anos pares, promove um concurso de produção de texto para alunos do $5^{\circ}$ ano do Ensino Fundamental ao $3^{\circ}$ ano do Ensino Médio, com um gênero específico para duas séries. Em 2010 , na sua segunda edição, a Olimpíada determinou os seguintes gêneros: poema para $5^{\circ}$ e $6^{\circ}$ anos do Ensino Fundamental; memórias literárias para $7^{\circ}$ e $8^{\circ}$ anos do Ensino Fundamental; crônicas para o $9^{\circ}$ ano do Ensino Fundamental e $1^{\circ}$ ano do Ensino Médio; e artigo de opinião para $2^{\circ}$ e $3^{\circ}$ anos do Ensino Médio (BRASIL, 2010).

3 Conforme explica Rodrigues (2005), Círculo de Bakhtin é uma expressão cunhada por pesquisadores contemporâneos para se referir ao grupo de intelectuais russos que se reunia regularmente no período entre 1919 e 1929, do qual fizeram parte Bakhtin, Volochinov e Medvedev.
} 
parecem explicitamente importantes em se tratando da Proposta Curricular de Santa Catarina (BRASIL, 1998). Sob a perspectiva sócio-histórica, por exemplo, parece significativa a busca de uma ação escolar mediadora da formação do aluno produtor de textos-enunciado em diferentes gêneros discursivos, tomando por base a proposição vigotskiana de que as relações intersubjetivas incidem sobre as construções intrassubjetivas (VIGOTSKI, 2007 [1978]). Já sob a perspectiva bakhtiniana dos gêneros do discurso, seguramente há uma sensibilidade em relação à forma com que os seres humanos usam a linguagem em suas práticas interacionais cotidianas e uma vontade de trazer para dentro do universo escolar os textos que circulam na vida "extramuros", mobilizando estratégias de ensino menos artificializadas e mais significativas sob o ponto de vista das práticas sociais.

Vale ressaltar, entretanto, que ambos os eixos teóricos não constituem construtos ocupados, na origem, com questões de ensino e aprendizagem. Parece que a contribuição que eles trouxeram para a educação, mesmo que indiretamente, foi a concepção de língua como objeto social, que acabou redundando na preocupação em empreender o ensino de língua materna ancorado em usos sociais da linguagem. Essa contribuição se estende, ainda, à concepção de sujeito e de texto em Bakhtin. A concepção de enunciado também é central para percebermos que texto é esse com o qual trabalhamos e ancora toda a prática de leitura/escuta, produção textual e análise linguística proposta por Geraldi (1997 [1991]). Vale, assim, levantar brevemente as principais contribuições de cada teoria para o ensino e a aprendizagem de língua materna, para, em seguida, partir para a análise dos textos produzidos pelos alunos participantes da pesquisa.

\section{O PROCESSO DE ENSINO FUNDADO EM BASES SOCIOINTERACIONISTAS}

Um dos principais conceitos vigotskiano que trouxe contribuições significativas para o ensino e aprendizagem de língua materna é o de zona de desenvolvimento imediato ${ }^{*}$ (ZDI). Considerando que o aprendizado $^{5}$ deve ser combinado de alguma maneira com o nível de desenvolvimento da criança, Vigotski (2007 [1978]) nomeia e descreve dois níveis de desenvolvimento. O primeiro, chamado de nivel de desenvolvimento real, é o que incluiu as funções mentais da criança ${ }^{6}$ já completadas; ou seja, tudo aquilo que a criança consegue fazer sozinha, sem nenhum tipo de ajuda. Se a criança só consegue realizar determinada atividade com ajuda de outra pessoa, então se trata do segundo nível, o de desenvolvimento potencial, que seria o mais indicativo do desenvolvimento mental de uma criança. É a partir desses dois conceitos que Vigotski cria a chamada zona de desenvolvimento imediato (doravante, ZDI):

Ela é a distância entre o nível de desenvolvimento real, que se costuma determinar através da solução independente de problemas, e o nível de desenvolvimento potencial, determinado através da solução de problemas sob a orientação de um adulto ou em colaboração com companheiros mais capazes. (VIGOTSKI, 2007 [1978], p. 97, grifo do autor)

Se para o autor o aprendizado impulsiona o desenvolvimento, o que se consubstancia na interação entre indivíduos, então a escola assume um papel de substancial importância nesse processo. Na ZDI, a ação de outros indivíduos incide mais efetivamente: "[...] o aprendizado escolar exerce significativa influência no desenvolvimento das funções psicológicas superiores, justamente na fase em que elas estão em amadurecimento" (REGO, 2002, p. 79-80). Para Vigotski (2007 [1978]), o "bom aprendizado" é aquele que se adianta ao desenvolvimento; ou seja, não apenas considera as capacidades já completadas pela criança, mas aquelas em fase de maturação - na Zona de Desenvolvimento Imediato -, olha o desenvolvimento mental prospectivamente.

O ensino escolar, portanto, deve se dirigir para esses estágios ainda não incorporados pelos alunos, servindo como um motor para alcançá-los: "[...] a escola tem o papel de fazer a criança avançar em sua compreensão do mundo a partir de seu desenvolvimento já consolidado e tendo como metas etapas posteriores, ainda não alcançadas" (KOHL DE OLIVEIRA, 1997, p. 62). Kohl de Oliveira (1997) também aponta que o professor

\footnotetext{
4. Segundo Paulo Bezerra (2001), tradutor da obra “A construção do pensamento e da linguagem”, a partir da versão russa, o termo, em português, que mais se aproxima do conteúdo da expressão russa é imediato e não proximal, expressão que o tradutor tributa como exótica. Adoto essa recomendação neste estudo.

$5 \mathrm{O}$ termo aprendizado é considerado aqui como sendo “[...] o processo pelo qual o indivíduo adquire informações, habilidades, atitudes, valores etc. a partir de seu contato com a realidade, o meio ambiente, as outras pessoas" (KOHL DE OLIVEIRA, 1997, p. 57).

6 Ainda que o autor refira a crianças, entendo passível a extensão desse conceito para diferentes faixas etárias.
} 
atua como um protagonista para incidir sobre a ZDI dos alunos, provocando o desenvolvimento que não ocorreria espontaneamente. E a própria interação entre os alunos também é essencial nesse processo: em um grupo heterogêneo, por exemplo, um aluno com o conhecimento mais avançado sobre determinado assunto pode contribuir no desenvolvimento dos outros. A ação do professor e das próprias crianças no desenvolvimento individual é peça-chave em uma proposta de ensino escolar de base vigotskiana.

Vigotski (2007 [1978]) reavalia a questão da imitação no aprendizado. Contrariando a crença de que a imitação é um processo puramente mecânico, o autor aponta em seus estudos a conclusão de que uma pessoa só consegue imitar o que está no seu nível de desenvolvimento, pois implica uma “[...] reconstrução individual daquilo que é observado nos outros. [...] criação de algo novo a partir do que observa” (KOHL DE OLIVEIRA, 1997, p. 63). E a criança só pode imitar, portanto, o que está em processo de aprender, por isso a imitação, para Vigotski, pode contribuir para o desenvolvimento mental, uma vez que pode sinalizar em que nível de desenvolvimento intelectual a criança se encontra; em outras palavras: “[...] só se pode ensinar à criança o que ela já for capaz de aprender. A aprendizagem é possível onde é possível a imitação. Logo, a aprendizagem deve orientar-se nos ciclos já percorridos de desenvolvimento, no limiar inferior da aprendizagem" (VIGOTSKI, 2001 [1934], p. 332).

Outra contribuição do ensino escolar no desenvolvimento do sujeito, segundo Vigotski, é na formação de conceitos. Segundo Rego (2002, p. 76), conceitos são entendidos pela perspectiva vigotskiana como um “[ [...] sistema de relações e generalizações contido nas palavras e determinado por um processo histórico cultural: são construções culturais, internalizadas pelos indivíduos ao longo de seu processo de desenvolvimento”. Em suas obras, Vigotski aponta para dois tipos de conceitos: espontâneos ou cotidianos e científicos. Os conceitos espontâneos são construídos a partir da manipulação e da vivência direta da criança. Nas interações cotidianas, a mediação do adulto acontece espontaneamente no processo de utilização da linguagem, no contexto das situações imediatas - ou seja, suas palavras referem-se a elementos presentes nas situações. Já os conceitos científicos relacionam-se àqueles eventos não diretamente acessíveis à observação ou ação imediata da criança: são os conceitos sistematizados, adquiridos nas interações escolarizadas. Conceitos incluem-se em um sistema de abstrações graduais, com diferentes níveis de generalizações. Para Newman e Holzman (2002), é possível caracterizá-los da seguinte maneira: os científicos seriam, basicamente, os aprendidos em ambiente escolar, enquanto os espontâneos seriam aprendidos no curso da vida diária.

Em relação ao desenvolvimento da linguagem escrita nas crianças, foco de nosso estudo, Vigotski (2007 [1978]) levanta três conclusões de caráter prático. A primeira é que, para o autor, seria natural transferir o ensino da escrita para a pré-escola, uma vez que os experimentos de Hetzer, relatados em sua obra, mostram que as crianças mais novas são capazes de descobrir a função simbólica da escrita. Vigotski, porém, ressalta aqui a importância de o ensino da leitura e da escrita ter uma “utilidade prática” para a criança, e não como simples habilidade motora: "A leitura e a escrita devem ser algo de que a criança necessite” (VIGOTSKI, 2007 [1978], p. 143). Essa ressalva leva à segunda conclusão do autor, de que a escrita deve ter significado para as crianças: “[ [..] uma necessidade intrínseca deve ser despertada nelas [nas crianças] e a escrita deve ser incorporad̄a a uma tarefa necessária e relevante para a vida” (VIGOTSKI, 2007 [1978], p. 144). Por fim, o último ponto levantado pelo autor é a necessidade de a escrita ser ensinada naturalmente, precedida pelos estágios de desenhar e brincar.

\section{O SOCIOINTERACIONISMO DISCURSIVO DE GENEBRA: DIDATIZANDO CONCEITOS BAKHTINIANOS}

É preciso apontar ao menos dois conceitos fundamentais na teoria bakhtiniana que, assim como os pressupostos sociointeracionistas discutidos anteriormente, contribuem significativamente para o ensino escolar: são as definições de enunciado (e, consequentemente a concepção de texto como enunciado) e gêneros discursivos. Sobre o primeiro conceito, para Bakhtin, o discurso materializa-se na forma de enunciados: "O emprego da língua efetua-se em forma de enunciados (orais e escritos) concretos e únicos, proferidos pelos integrantes desse ou daquele campo da atividade humana” (BAKHTIN, 2003 [1979], p. 261); ou seja, “[ [...] o discurso só pode existir de fato na forma de enunciações concretas de determinados falantes, sujeitos do discurso" (BAKHTIN, 2003 [1979], p. 274). Com essas afirmações, Bakhtin define o enunciado como a unidade real e concreta da comunicação discursiva. $\mathrm{O}$ autor caracteriza ainda os enunciados e, consequentemente, os discursos como sendo "[...] pleno[s] de palavras do outro, de um grau vário de alteridade ou de assimilidade, de um grau vário de aperceptilidade e de relevância. Essas palavras dos outros 
trazem consigo a sua expressão, o seu tom valorativo que assimilamos, reelaboramos, e reacentuamos" (BAKHTIN, (2003 [1979], p. 294-295).

O enunciado, portanto, possui caráter dialógico: todo enunciado é uma resposta ao que já foi dito e espera uma nova resposta. "Qualquer enunciação, por mais significativa e completa que seja, constitui apenas uma fração de uma corrente de comunicação ininterrupta” (BAKHTIN, 2004 [1929], p. 123). Os enunciados entrelaçam-se, assim, numa corrente de "diálogos" em que o sentido não tem fim. Não pode haver enunciados isolados; um enunciado sempre pressupõe enunciados anteriores e posteriores, pois cada um é o elo de uma cadeia e não pode ser estudado fora dessa cadeia. Todas essas características são passíveis de serem "aplicadas" ao texto: todo texto, assim, também possui função ideológica particular, um locutor e um interlocutor, relações dialógicas com outros textos.

Os enunciados ainda são dialogicamente tipificados nas diversas interações, constituindo o que Bakhtin denomina de gêneros do discurso. Bakhtin os define como "tipos relativamente estáveis de enunciados" ou "formas relativamente estáveis e normativas do enunciado" (RODRIGUES, 2005, p. 163). Rodrigues (2005) explica a noção bakhtiniana de "tipo" como "modos sociais de discurso": "[ …] tipificação social dos enunciados que apresentam certos traços (regularidades) comuns, que se constituíram historicamente nas atividades humanas, em uma situação de interação relativamente estável, e que é reconhecida pelos falantes" (RODRIGUES, 2005, p. 164).

Apesar desses conceitos estarem tão fortemente presentes na esfera escolar, conforme já mencionado, as teorizações bakhtinianas não tiveram como foco central de atenção o ensino e a aprendizagem de línguas; trata-se de uma abordagem mais ampla, o plano da filosofia da linguagem. Encontramos nessas teorizações, assim, um "vasto conjunto conceitual", e não um "modelo analítico". Na falta desse modelo para uma análise da interação verbal, têm surgido estudos que buscam construir ancoragens modelares voltadas à educação. Um exemplo é o grupo de pesquisadores da Unidade de Didática de Línguas da Faculdade de Psicologia e Ciências da Educação da Universidade de Genebra, cujos principais representantes são Jean-Paul Bronckart, Bernard Schneuwly e Joaquim Dolz. Esses estudiosos, sobretudo Bronckart, estabeleceram uma visão psicossociológica dos gêneros, na corrente denominada Interacionismo Sociodiscursivo (doravante, ISD), que traz implicações para o ensino de gêneros. Machado (2005) define essa corrente com as seguintes características:

Tendo em Vygotsky sua fonte de referência e com uma abordagem marxiana, logo dialética, dos fenômenos psicológicos, esses autores colocam-se em favor da reunificação da psicologia, à qual atribuem uma dimensão social e cuja finalidade central seria elucidar as condições de emergência e de funcionamento do pensamento consciente humano. (MACHADO, 2005, p. 238)

A expressão interacionismo social, segundo Bronckart (1999, p. 21, grifos do autor), inclui diversas correntes da filosofia e das ciências humanas, que teriam em comum a tese de que “[...] as propriedades específicas das condutas humanas são o resultado de um processo histórico de socialização, possibilitado especialmente pela emergência e pelo desenvolvimento dos instrumentos semióticos.”.

O método de análise de texto proposto pelo ISD possibilitou a construção do conceito de "modelo didático de gênero", segundo Machado (2005). Ao utilizarem esse método, juntamente com outros estudos de discurso compatíveis, geralmente com finalidades didáticas, levantou-se a hipótese de que textos socialmente considerados como pertencentes a determinado gênero apresentam algumas características semelhantes. Esses "modelos didáticos", assim, poderiam guiar a elaboração e a avaliação de material didático, além da avaliação das capacidades de produção textual dos alunos. E essa parece ser a grande contribuição do ISD para o ensino e a aprendizagem de gêneros discursivos (ou gêneros de textos, nas palavras dos autores).

Os autores do ISD, portanto, constroem uma proposta que representaria uma modelização/didatização do conceito de gêneros do discurso de Bakhtin. Bronckart (1999) sugere uma abordagem didática que inicia o ensino da língua pelas atividades de leitura e de produção de textos, articulando posteriormente atividades de inferência e codificação das regularidades observáveis no corpus dos textos mobilizados - ou seja, exemplares de gênero configurados em texto. Schneuwly e Dolz (2004) organizam essa proposta no chamado modelo de ensino modular, aplicável em todas as seriações. A partir do postulado de que a comunicação oral e escrita pode e deve ser ensinada sistematicamente, os autores adotam a estratégia denominada sequência didática: "[...] uma sequência de módulos de ensino, organizados conjuntamente para melhorar uma determinada prática de linguagem" (SCHNEUWLY; DOLZ, 2004, p. 51). Em outras 
palavras: “[ $[.$.$] é um conjunto de atividades escolares organizadas, de maneira sistemática, em torno de um$ gênero textual oral ou escrito" (DOLZ; NOVERRAZ; SCHNEUWLY, 2004, p. 97). Essa sequência tem como base, portanto, os gêneros textuais, vistos como práticas de linguagem historicamente construídas:

As sequências didáticas instauram uma primeira relação entre um projeto de apropriação de uma prática de linguagem e os instrumentos que facilitam essa apropriação. Desse ponto de vista, elas buscam confrontar os alunos com práticas de linguagem historicamente construídas, os gêneros textuais, para lhes dar a possibilidade de reconstruí-las e delas se apropriarem. Essa reconstrução realiza-se graças à interação de três fatores: as especificidades das práticas de linguagem que são objeto de aprendizagem, as capacidades de linguagem dos aprendizes e as estratégias de ensino propostas pela sequência didática. (SCHNEUWLY; DOLZ, 2004, p. 51, grifos dos autores)

O manual das Olimpíadas de Português adotado na turma participante de pesquisa é uma simulação de uma sequência didática, que traz várias oficinas a serem trabalhadas "em ordem", todas com foco em um único gênero - a crônica -, determinado para uma seriação específica - $1^{\circ}$ ano do Ensino Médio. A sequência é a mesma defendida por esses autores: apresentação da situação - ou seja, apresentação do projeto de comunicação que será realizado -; primeira produção textual; módulos para trabalhar com os "problemas" que apareceram na primeira produção, dando "instrumentos" para os alunos - quantos forem necessários -; produção final.

Com base em todos esses pressupostos teóricos, a intervenção desta pesquisa propôs empreender uma elaboração didática (HALTÉ, 2008 [1998]) a partir do manual das Olimpíadas de Português, haja vista que não é possível tomar o pensamento bakhtiniano como aporte direto para a ação pedagógica, apesar de haver outras operacionalizações do pensamento de Bakhtin - o autor apenas não elaborou um modelo para aplicação didática direta. A proposta, assim, defendeu o trabalho com a língua em uso, tendo os gêneros como (mega)instrumentos, tal qual propõem Schneuwly e Dolz (2004). Vamos então aos textos produzidos pelos alunos durante a pesquisa.

\section{OS RESUlTADOS DO TRABALHO COM O GÊNERO CRÔNICA: A (NÃO) FORMAÇÃO DE PRODUTORES TEXTUAIS NA AULA DE PORTUGUÊS}

Os alunos participantes da pesquisa produziram duas versões de crônicas: uma inicial produzida sob orientação da professora, e uma final feita para o blog da turma construído durante a intervenção ${ }^{7}$. Após seis aulas de leituras e estudo das crônicas, seguindo a sequência didática sugerida pelo manual das Olimpíadas de Português (BRASIL, 2010), a professora da escola distribuiu jornais aos alunos e pediu que cada um produzisse uma crônica a partir de uma manchete escolhida. Não incidi sobre esse encaminhamento metodológico, embora fosse minha compreensão, tal qual menciona Geraldi (1997 [1991]), que, para escrever, temos de ter o que dizer. $\mathrm{O}$ contato com uma manchete de jornal pode ser estratégia desencadeadora, mas o ato de escrever seguramente demanda alimentação temática de outra ordem. Vale agregar a isso a discussão maior: temos de ter a quem dizer e razões para dizer, eis aqui a modalidade escrita da língua instituindo (ou não) relações interpessoais, em esferas específicas da atividade humana, para propósitos específicos, tal qual prevê o ideário bakhtiniano (2003 [1953/54]).

Na primeira aula, os alunos deveriam apenas escolher um assunto para a crônica, a partir das manchetes, e anunciar suas escolhas à professora, que anotou os temas selecionados. Eles poderiam pesquisar mais sobre o assunto em casa para, na segunda aula, produzir a crônica em sala. Mediante o comportamento dos alunos nas seis aulas anteriores - muitas faltas, pouca atenção e participação nas atividades -, tanto quanto mediante a natureza restrita do encaminhamento da produção escrita, o resultado obtido nessa primeira produção textual já era esperado, conforme a avaliação da própria professora: pouquíssimos alunos produziram realmente um texto-enunciado no gênero crônica. Primeiramente, o número de textos entregues foi extremamente baixo - apenas $47 \%$ dos alunos o fizeram -, assim como todas as atividades propostas pelos professores, consequência do alto número de faltas e do baixo nível de engajamento dos alunos nos eixos propostos para o desenvolvimento de cada aula. Um segundo ponto a considerar é o fato de que, em tais escritos, não se percebe nenhuma relação com as manchetes escolhidas, mas sim um conjunto de temas coincidentes com os levantados pela bibliotecária da escola, em entrevista, como sendo os prediletos dos

\footnotetext{
7 Nas legendas dos textos, identificarei os alunos por número de acordo com a ordem em que aparecem na lista de chamada da professora participante da pesquisa.
} 
alunos - gravidez, futebol, drogas, relacionamento. A grande maioria fixou-se numa forma possível do gênero crônica, de acordo com as leituras feitas em sala de aula: como lemos várias crônicas configuradas sob forma de diálogos diretos, a exemplo do texto Aquilo, de Luís Fernando Veríssimo (em anexo), 73\% dos alunos construíram seu texto tomando o "modelo" aprendido, conforme os exemplos a seguir (os textos não estão identificados em razão de demandas éticas):

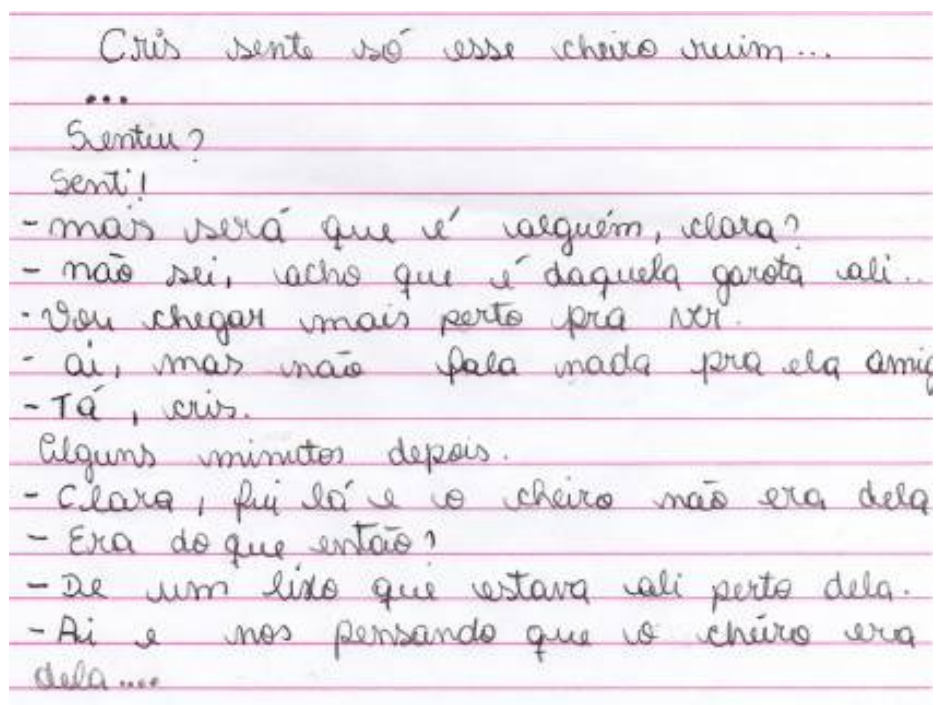

Exemplo 1: aluno n. 15.

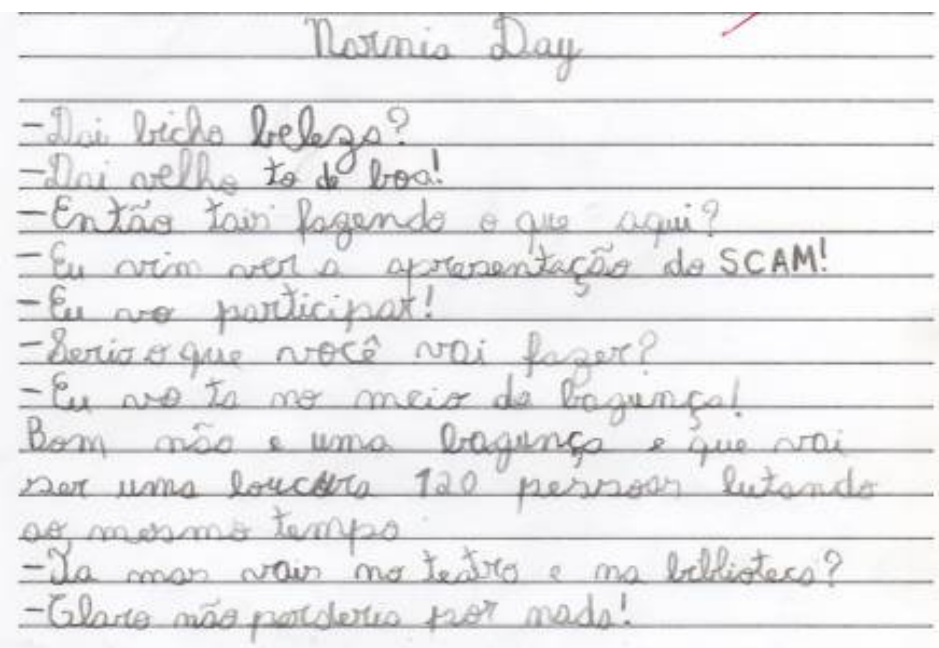

Exemplo 2: aluno n. 26.

Esses textos parecem não corresponder a materializações do gênero crônica e, ainda, suscitam reflexões sobre a natureza do domínio da modalidade escrita por parte desses alunos, cujo nível de escolarização é o primeiro ano do Ensino Médio. Produções como essas são ilustrativas da maior parte dos textos discentes produzidos no período da pesquisa. Parece clara a influência das crônicas trabalhadas em aula, nas quais o uso do diálogo direto era recurso recorrente, tanto quanto o humor. Parece que os alunos, assim, haviam entendido que crônica era um texto com diálogo direto, ou seja, uma compreensão muito circunscrita. Se, como vimos em seção anterior, a imitação só ocorre a partir daquilo que está no nível de desenvolvimento real do indivíduo (VIGOTSKI, 2007 [1978]), então compreender o restante demandava um nível de desenvolvimento mais efetivo sobre os usos da escrita, o que não era o caso.

Além do formato de diálogos diretos, os alunos também parecem ter se fixado no motivo de humor da crônica de Veríssimo: a ambiguidade referencial. Muitos deles parecem ter inferido ser essa uma "regra" do gênero crônica, como no exemplo abaixo: 


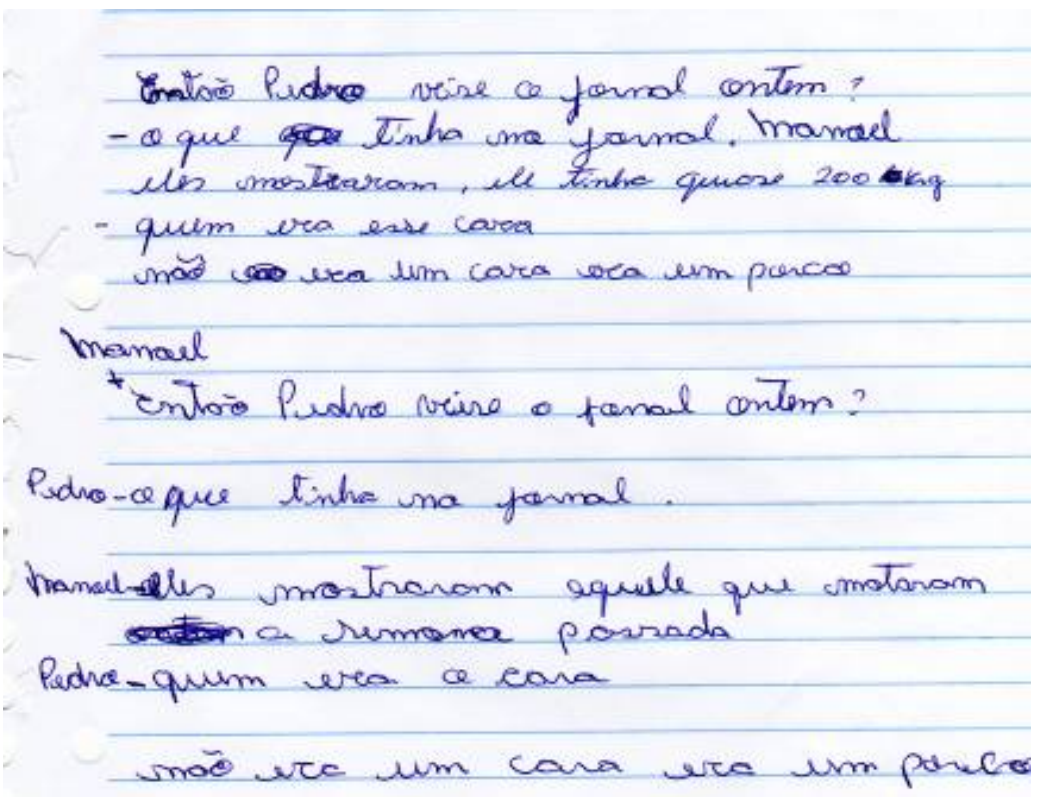

Exemplo 3: aluno n. 9.

Obviamente o efeito não é o mesmo, mas a intenção claramente parece ter sido seguir essa característica da crônica de Veríssimo. Escrever um final considerado "surpreendente", responsável pelo humor do texto, também apareceu em outras produções dos alunos que não se valeram do diálogo direto, como neste exemplo a seguir:

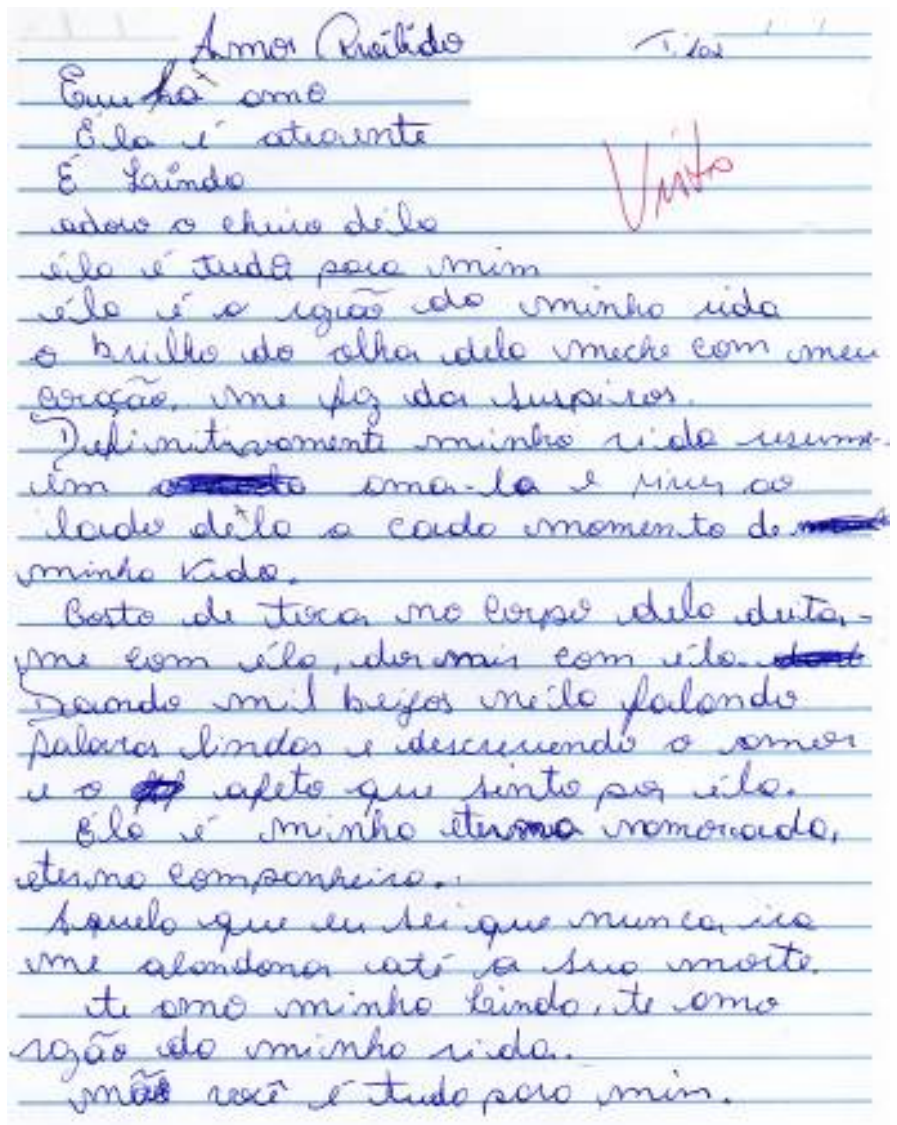

Exemplo 4: aluno n. 23.

Esse comportamento de tentar "copiar" a forma "aprendida" do gênero crônica parece sinalizar também que os alunos escrevem para a professora - temos aqui o sumiço do interlocutor acusado por Geraldi (1997 [1991]) -, ou seja, tentam alcançar o resultado que eles inferem que seja esperado pela professora. Vimos a defesa de Vigotski (2007 [1989]) sobre a importância de a escrita ter significado para as crianças, vista 
como uma tarefa necessária e relevante para a vida que parte de uma necessidade intrínseca. Parece que esses alunos não veem o processo sob essa perspectiva; ou seja, não houve uma necessidade intrínseca que despertasse a vontade de produzir uma crônica, por isso não significou para eles. Ainda, se Vigotski (2007 [1978]) mostra que a escrita, assim, pode vir a se tornar um "momento natural" no desenvolvimento da criança $^{8}$, parece que o trabalho de Língua Portuguesa naquela turma não teve esse alcance.

Outro ponto que emerge no texto anterior (exemplo 4) é a precariedade no domínio das estruturas linguísticas correspondentes à norma padrão escrita e a artificialidade de conteúdo, que acabam por deixar os textos difíceis de compreender, incoerentes e não coesos. Os problemas formais de escrita, como ortografia, concordância e até de codificação (como a junção de certas preposições com substantivo "demanhã", "detarde" -, presentes em outros textos) também chamam atenção por ocorrerem em uma turma de primeiro ano de Ensino Médio e traduzirem conhecimentos sobre segmentação da modalidade escrita (SCLIAR-CABRAL, 2003) que deveriam ter sido internalizados por ocasião dos primeiros anos do processo de escolarização. Tais problemas foram foco de correção da professora participante da pesquisa - podemos perceber a correção que ela fez nos textos em vermelho:

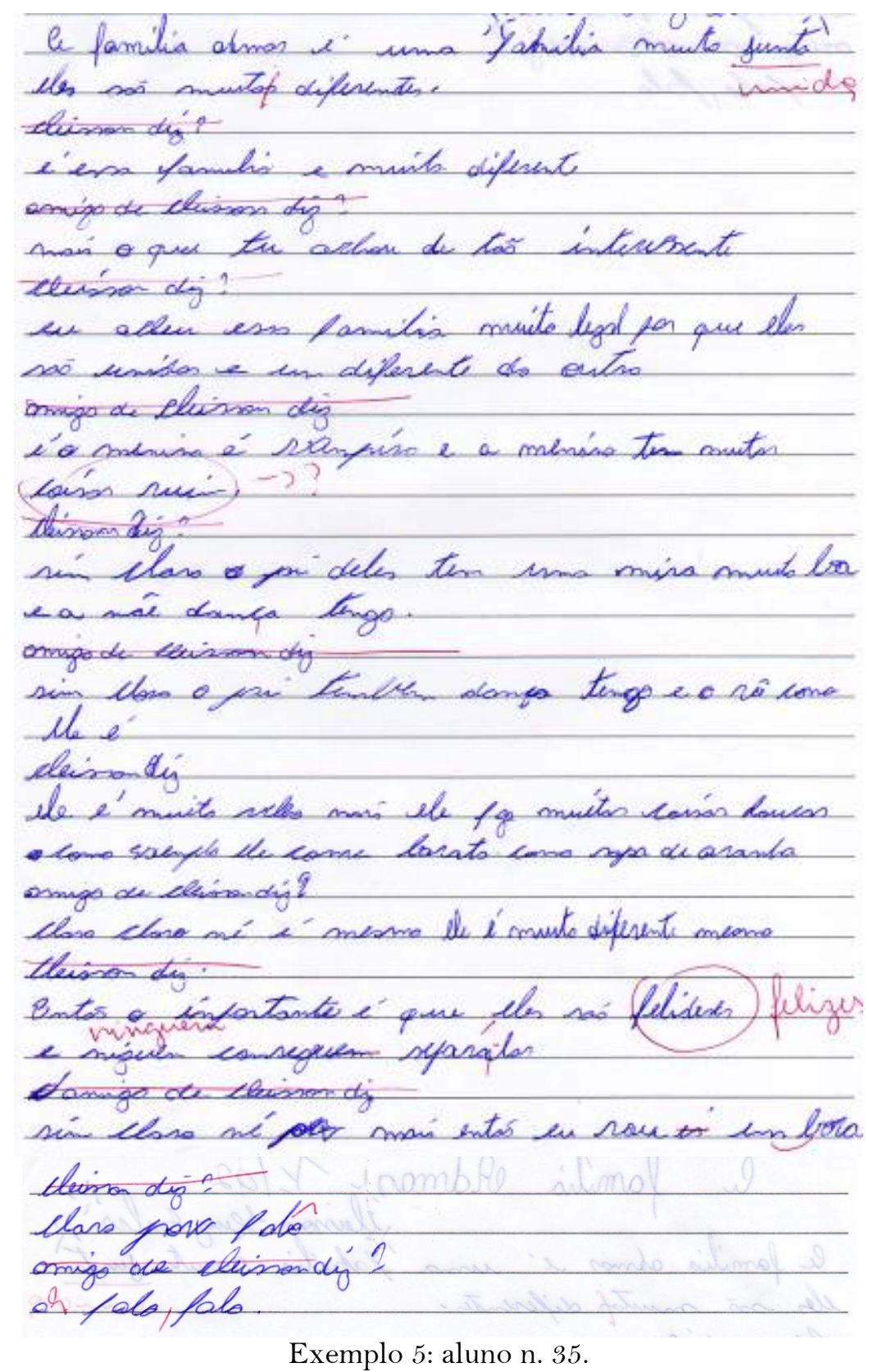

${ }^{8}$ Reitero que, embora essas afirmações refiram-se às crianças, entendo serem passíveis de extensão aos alunos em questão. 
Essas correções para refacção feitas pela professora indicam um trabalho com a dimensão textual sistêmica - aparece aqui objetivismo abstrato contra o qual se insurge Bakhtin (2004 [1929]), embora a escola se proponha a trabalhar com gêneros. Percebe-se, aqui, que a professora não incidiu sobre o fato de não serem crônicas, mas fez correções sistêmicas pontuais. Esse comportamento parece estar entranhado na escola que não concebe, assim, o texto como enunciado (RODRIGUES, 2005). Evidentemente o nível de alfabetismo dos alunos suscita uma ação focada no domínio do sistema alfabético e no domínio da norma padrão da língua, mas seguramente esse foco precisa ser compreendido sob outras bases metodológicas se a ancoragem teórica é bakhtiniana.

Se a escola, e consequentemente os alunos, focam na forma dos textos, é válido questionar: Será que temos enunciados de fato? Sim, mas são enunciados típicos da esfera escolar, fixados na forma do texto, e não em gêneros. Nessas produções textuais escritas, os alunos participantes da pesquisa esperam de fato a reação resposta do interlocutor? E há um interlocutor? Conforme afirmado anteriormente, parece que eles escrevem apenas para a professora. Se cada gênero possui uma concepção típica de destinatário, segundo Bakhtin (2003 [1953/54]), quem seriam os destinatários da crônica dentro e fora da escola? Vimos nesses textos produzidos uma artificialidade que parece ser típica da esfera escolar (HALTÉ, 2008 [1998]); no entanto, possivelmente a agravante não seja propriamente a artificialidade constitutiva, mas a histórica ausência da dimensão interacional do processo de produção escrita: são anos produzindo textos para o professor ler. Como alterar isso em um contexto como o vivenciado parece ser o grande desafio das atividades escolares de produção textual, e Geraldi (1997 [1991]) chamou atenção para esse desafio há duas décadas.

Se, para Bakhtin (2004 [1929]), todo enunciado é um elo de uma cadeia ininterrupta, então não se pode conceber os textos desses alunos como enunciados plenos, para os propósitos de ensino e aprendizagem, pois não se vê neles as marcas ressaltadas por Bakhtin (2004 [1929]): o toque com os milhares de fios dialógicos, a existência de um participante ativo do diálogo social, entre tantos outros desdobramentos. Essa concepção dos textos como artefatos, e não como enunciados, advém, em meu entendimento, do trabalho da escola focado apenas na dimensão verbal (RODRIGUES, 2005), conforme mencionado. Ainda, se a situação da interação e os participantes dessa mesma interação dão forma e estilo à enunciação (BAKHTIN, 2004 [1929]), possivelmente por isso as produções textuais mostraram-se tão infrutíferas e precárias: a situação é a sala de aula, os alunos não conseguem ainda vislumbrar um espectro interacional mais amplo. A artificialidade das relações propostas na escola - e possivelmente o fato de muitas das propostas tematizarem conceitos que não estão minimamente exauridos de experimentação (VIGOTSKI, 2001 [1934]) e cuja abstração não incide sobre a zona de desenvolvimento imediato (VIGOSTKI, 2007 [1978]), mas para muito além dela - seriam as responsáveis pela precariedade nas produções dos alunos.

Esses textos foram corrigidos pela professora participante da pesquisa e refeitos para a publicação no blog construído pela turma. A professora, na verdade, empreendeu duas correções nos textos: a primeira, manualmente, nos textos manuscritos; depois foi dado um tempo para os alunos refazerem os textos e digitá-los; e, por fim, uma última correção da professora feita no computador e enviada para os e-mails dos alunos. Com a intenção de seguir a proposta de Geraldi (1997 [1991]) para o trabalho com produção textual - ter o que dizer, uma razão para dizer, para quem dizer, que o locutor se constitua como tal e estratégias - e ainda com o propósito de aproveitar a tecnologia disponível na escola, aproximando-se da realidade dos alunos, foi proposta a criação de um blog para publicação dos textos produzidos. Eis a busca pelo interlocutor real ou representante médio do grupo social, tal qual defende Bakhtin (2004 [1929]) ao discutir a interação verbal.

Se a relação do sentido é sempre dialógica, ou seja, a "coisa" da qual se fala não existe mais só em si e para si, mas "para algum outro" (BAKHTIN, 1997b [1979], p. 343), isso é tudo o que não aconteceu nessas vivências da pesquisa. O professor não é esse outro para quem o aluno escreve porque as relações não são simétricas. Simular não tem bastado; por isso a proposta do blog. Parece que as novas tecnologias abrem a perspectiva de escrever de fato para esse outro, mas pedras institucionais obstaculizam esse avanço. $\mathrm{O}$ planejamento da intervenção, por exemplo, chegou a prever a divulgação dos textos pela rádio da escola, que estava desativada, mas, pelos percalços no caminho, não foi possível empreender a ativação da rádio. As últimas aulas do período de intervenção, assim, foram todas no laboratório de informática, onde os alunos produziram as crônicas e desenvolveram o blog, processo ao qual todos foram convidados a participar, mas que obteve notadamente um baixo nível de engajamento. 
Outro ponto que se destacou na produção das crônicas foi certa "falta de perspectiva" por parte dos alunos, ao demonstrarem não se sentirem "capazes" de produzir um texto em tal gênero. Em uma das últimas aulas de refacção das crônicas, quando a professora começou a cobrar dos alunos que ainda não haviam feito nem a primeira versão, um aluno bem pouco participativo veio me perguntar sobre o que ela estava falando. Ao explicar nossa proposta, ele me perguntou surpreso: Ela quer que eu escreva uma crônica? Eu? (Nota n. 215, diário de campo, ALP30, $1^{\circ}$ ano, 22/06/2010). E ele não produziu nenhum texto.

Partindo das teorizações bakhtinianas acerca do conceito de alteridade (BAKHTIN, 1997a [1979]), que afirma que tomamos consciência de nós mesmos, criamos uma representação de nós mesmos, pela palavra do outro, pergunto: Não estariam esses alunos internalizando representações construídas pelos outros sobre seu próprio percurso? Esse descaso não seria, em boa medida, uma internalização de representações alheias que já os veem como indiferentes? Se as interações propostas nas aulas não acontecem, ou melhor, se a atitude responsiva dos alunos é, geralmente, o silêncio ou o aparente desinteresse pelo tópico em discussão, outros tipos de interações se dão, como essas que internalizariam tais pensamentos, tornando-se "pedras no meio do caminho" na formação do aluno produtor de textos-enunciado. Será que haveria nesta escola um discurso de fracasso assumido a priori em relação aos alunos, que serviria de excedente de visão e auditório social (BAKHTIN 2003 [1979]) a esses mesmos alunos? Esse excedente de visão do outro em relação a esses alunos não estaria marcado por preconstruídos e, em boa medida, não estaria contribuindo para que esses preconstruídos se instaurassem ali? Em outras palavras: a escola acredita de fato que esses alunos podem aprender o que está previsto para que aprendam? E, por outro lado, não estaria prevendo "pouco" em se tratando desse o que ensinar?

Esses poucos trechos selecionados sinalizam para o fato de que a grande maioria dos alunos não se apropriou de fato do gênero crônica. Pode-se concluir que trabalhar crônica com aqueles alunos parece ter sido uma proposta muito além da zona de desenvolvimento imediato deles (VIGOTSKI, 2007 [1978]): eles não tinham noção acerca de como usar a modalidade escrita para finalidades interacionais dessa natureza. Ainda, a não familiaridade com esse gênero indica que esses textos não compõem suas vivências, logo a crônica deve ser tomada como um conceito científico (VIGOTSKI, 2001 [1934]) para esses alunos - ou seja, não saturado de experiência, com uma abordagem que só se dá no plano escolar. Parece que é exatamente o que significa a crônica para esses estudantes: eventos não diretamente acessíveis à observação ou ação imediata. Se os conceitos científicos são os aprendidos em ambiente escolar e os espontâneos são os aprendidos no curso da vida diária (NEWMAN; HOLZMAN, 2002), isso explica a artificialidade da crônica na vida deles, como conceito científico.

Conclui-se, portanto, que a crônica não faz parte da vida desses alunos, ou seja, não constitui um conceito espontâneo, não está saturada de experiência. Por outro lado, a ação escolar não conseguiu facultar aos alunos a construção da abstração e das generalizações sobre a crônica: parece que não houve aprendizado porque se trata de um conceito cuja apropriação está muito longe da zona de desenvolvimento imediato desses alunos; eles não têm tido compreensão básica sobre como a escrita funciona nos gêneros secundários; não têm experienciado de fato isso. Infere-se, assim, que a escola precisa conscientizar os alunos sobre os conceitos científicos como dentro de um sistema (VIGOTSKI, 2001 [1934]), o que não se conseguiu empreender com o gênero crônica.

Em outras palavras, acreditando que o ensino escolar deve intervir no desenvolvimento do aluno a partir da zona de desenvolvimento imediato, parece que, no caso do trabalho empreendido com o gênero crônica, a aprendizagem não moveu o desenvolvimento porque a abordagem escolar estava inadequada para as experiências dos alunos com os usos da modalidade escrita; ou seja, a faixa etária em que se encontravam não constituía informação suficiente para as escolhas escolares, que impõe "crônica é adequada para alunos de primeira série’. Nesse grupo, não havia experienciações com a modalidade escrita que facultassem a entrada da crônica naquele momento - as características dos textos produzidos confirmam isso. Mesmo advogando em prol da defesa do uso dos gêneros discursivos como força centrífuga que traz para a escola o plurilinguismo, o heterogêneo (BUNZEN apud ROJO, 2008), na empiria esses resultados mostram que isso não ocorreu naquela ambientação, pois mesmo o que é centrífugo termina por virar centrípeto: a crônica virou mero artefato escolar. 


\section{CONSIDERAÇÕES FINAIS}

Este artigo tentou mostrar que todas essas atividades de escrita, posteriores a atividades de leitura, não resultaram na apropriação significativa do gênero crônica por parte dos alunos, o que pode ser evidenciado nas produções textuais empreendidas. O desafio da escola não é apenas disponibilizar textos de certos gêneros discursivos caros a essa instituição, a exemplo da crônica, mas inserir os alunos na heterogeneidade axiológica constitutiva dos discursos - o teor polifônico apontado por Faraco (2007); ou seja, mostrar-lhes o tanto de vozes que ecoam sobre os diferentes temas, inseri-los na heteroglossia dialogizada. É para isso que estudamos a linguagem na escola. $\mathrm{O}$ aluno precisa aprender, assim, a perceber essa multiplicidade de vozes presentes e dialogar com elas, assumindo uma posição de interlocutor. Este é outro grande desafio na formação do leitor e produtor de textos-enunciado: ensiná-lo a dialogar com o texto, com ele mesmo e com outros textos, tal qual defende Bakhtin (1997b [1979]); evidentemente para isso, importa a rendição à insistência de teóricos cognitivistas como Scliar-Cabral (2003), pois o aluno precisa decodificar o texto materializado no gênero, ou seja, precisa estar inteiramente alfabetizado. Dados do Inaf (2009) mostram que, no Ensino Médio, os níveis de alfabetismo pleno ainda não estão consolidados.

Assim, parte dos problemas apresentados nas produções textuais desses alunos parece relacionar-se com a leitura dos mesmos: ambos os processos estão interligados no funcionamento da aula e não devem ser separados, pois um é consequência do outro. As produções textuais dos alunos foram, portanto, um reflexo do "tipo" de leitura que eles empreendem por meio do qual materializam o conhecimento construído sobre o gênero trabalhado. Em outras palavras: eles entenderam o gênero crônica como um diálogo simples com um final "engraçado", e essa perspectiva visibilizou-se nas produções textuais escritas. Se eles apresentam problemas de decodificação, eliciados na leitura em voz alta, também apresentam problemas de codificação na escrita, o que se estende a conhecimentos básicos como a segmentação do contínuo da fala. Eis possíveis representações de níveis de alfabetismo básico - e não pleno - que se visibilizam nas estatísticas do Inaf (2009) no Ensino Médio. Sem dúvida, trata-se de um problema linguístico socialmente relevante (MOITA LOPES, 2006) a requerer atenção do linguista aplicado.

Trata-se, enfim, de desafios caros à atuação da escola na formação de alunos produtores de textosenunciado de gêneros discursivos diversos, sobretudo os secundários. Antes de mais nada, essa formação exige o desenvolvimento da consciência de que o signo serve como uma "arena" para a luta de classes, como "produto da interação viva das forças sociais" (BAKHTIN, 2004 [1929]); e, ainda, que a língua é povoada de intenções, totalmente acentuada (BAKHTIN, 1998 [1975]). Desse modo, enriquecer a produção textual escrita demanda essa ancoragem teórica no ato de fazer perguntas sobre um texto e no ato de apontar caminhos na refacção de um texto. Em relação especificamente à produção textual, o aluno precisa também posicionar-se frente a novos valores; e propor-se a estabelecer relações com o outro por meio de crônicas implica valorar esse tipo de interação, o que não se dá nas vivências intersubjetivas desses alunos - e, se não se dá nessas vivências, não se dará também no plano intrassubjetivo (VIGOTSKI, 2007 [1978]). Se a autoria implica, assim, relação dialógica (BAKHTIN, 2005 [1963]), eis o desafio da escola ao propor a produção textual como exercício para implementar práticas de uso de língua: trazer à consciência a condição desses alunos de usuários da língua nessas novas práticas.

\section{REFERÊNCIAS}

ANTUNES, Irandé. Aula de Português: encontro e interação. São Paulo: Parábola Editorial, 2003. (Série Aula; 1).

BAKHTIN, Mikhail. O discurso em Dostoievski. In: Problemas da poética. Trad. Paulo Bezerra. 3. ed. Rio de Janeiro: Forense Universitária, 2005 [1963]. p. 181-275.

[VOLOSHINOV, V. N]. Marxismo e filosofia da linguagem: problemas fundamentais do método sociológico na ciência da linguagem. Trad. Michel Lahud e Yara F. Vieira. 11. ed. São Paulo: Hucitec, 2004 [1929].

O autor e a personagem na atividade estética. In: Estética da criação verbal. Trad. Paulo Bezerra. 4. ed. São Paulo: Martins Fontes, 2003 [1979]. p. 3-194.

Os gêneros do discurso. In: Estética da criação verbal. Trad. Paulo Bezerra. 4. ed. São Paulo:

Martins Fontes, 2003 [1953/54]. p. 261-306. 
O discurso no romance. In:

Paulo: Hucitec, 1998 [1975]. p. 72-163.

Questões de literatura e estética: a teoria do romance. 4. ed. São

. Apontamentos 1970-1971. In: . Estética da criação verbal. Trad. Maria Ermantina Galvão G.

Pereira. 2. ed. São Paulo: Martins Fontes, 1997a [1979]. p. 369-414.

O problema do texto. In: . Estética da criação verbal. Trad. Maria Ermantina Galvão G.

Pereira. 2. ed. São Paulo: Martins Fontes, 1997b [1979]. p. 327-358.

BATISTA, Antônio Augusto Gomes. Aula de Português: discurso e saberes escolares. São Paulo: Martins Fontes, 1997. (Texto e Linguagem).

BRASIL. Olimpíadas de Lingua Portuguesa. Brasília: MEC, 2010.

Parâmetros Curriculares da Educação Nacional - Língua Portuguesa. Secretaria de Educação Fundamental. Brasília/DF, 1998.

BRITTO, Luiz Percival Leme. A sombra do caos: ensino de língua x tradição gramatical. Campinas, SP: ALB: Mercado de Letras, 1997. (Coleção Leituras no Brasil).

BRONCKART, Jean-Paul. Atividade de linguagem, textos e discursos. Por um interacionismo sociodiscursivo. Trad. Anna Rachel Machado, Péricles Cunha. São Paulo: EDUC, 1999.

DOLZ, Joaquim; SCHNEUWLY, Bernard. Gêneros e progressão em expressão oral e escrita - elementos para reflexões sobre uma experiência suíça (francófona). In: . Gêneros orais e escritos na escola. Trad. e org. Roxane Rojo e Glaís Sales Cordeiro. Campinas, SP: Mercado de Letras, 2004. p. 95-128. (Coleção As faces da Lingüística Aplicada).

DOLZ, Joaquim; NOVERRAZ, Michele; SCHNEUWLY, Bernard. Seqüências didáticas para o oral e a escrita: apresentação de um procedimento. In: SCHNEUWLY, Bernard; DOLZ, Joaquim. Gêneros orais e escritos na escola. Trad. e org. Roxane Rojo e Glaís Sales Cordeiro. Campinas, SP: Mercado de Letras, 2004. p. 95-128. (Coleção As faces da Lingüística Aplicada).

FARACO, Carlos Alberto. O estatuto da análise e interpretação dos textos do círculo de Bakhtin. In: GUIMARÃES, Ana Maria de Mattos; MACHADO, Anna Raquel; COUTINHO, Antônia. (Orgs.). $O$ interacionismo sociodiscursivo: questões epistemológicas e metodológicas. Campinas, SP: Mercado de Letras, 2007.

FISCHER, Steven. História da leitura. São Paulo: UNESP, 2006.

GERALDI, João Wanderley. Portos de passagem. 4. ed. São Paulo: Martins Fontes, 1997 [1991].

GRAFF, Harvey J. Os labirintos da alfabetização: reflexão sobre o passado e o presente da alfabetização. Porto Alegre: Artes Médicas, 1994.

HALTÉ, Jean-François. O espaço didático e a transposição. Fórum Lingüístico, Florianópolis, p. 117-139, jul./dez. 2008 [1998].

INAF BRASIL 2009. Disponível em <http://www.ipm.org.br>. Acesso em: 14 set. 2010.

KOHL DE OLIVEIRA, Marta. Vygotsky: Aprendizado e desenvolvimento: um processo sócio-histórico. São Paulo: Scipione, 1997. (Pensamento e ação no magistério).

KLEIMAN, Angela B. (Org.) Modelos de letramento e as práticas de alfabetização na escola. In: significados do letramento: uma nova perspectiva sobre a prática da escrita. Campinas, SP: Mercado dos Letras, 2001 [1995]. p.15-64.

Oficina de leitura. 8. ed. Campinas, SP: Pontes, 2001 [1989].

MACHADO, Anna Rachel. A Perspectiva interacionista sociodiscursiva de Bronckart. In: MEURER, J. L.; BONINI, Adair; MOTTA-ROTH, Désirée (Orgs.). Gêneros: teorias, métodos, debates. São Paulo: Parábola Editorial, 2005. p. 237-259.

MOITA LOPES, Luiz Paulo da. (org.). Por uma linguística aplicada indisciplinar. São Paulo: Parábola, 2006. (Língua[gem]; 19).

NEWMAN, Fred; HOLZMAN, Lois. Lev Vygotsky: cientista revolucionário. Trad. Marcos Bagno. São Paulo: Edições Loyola, 2002. 
PETIT-JEAN, André. Importância e limites da noção de transposição didática para o ensino do francês. Fórum Lingüístico, Florianópolis, p. 83-116, jul./dez. 2008 [1998].

REGO, Tereza Cristina. Vygotsky: uma perspectiva histórico-cultural da educação. 13. ed. Petrópolis: Vozes, 2002.

RODRIGUES, Rosângela Hammes. Os gêneros do discurso na perspectiva dialógica da linguagem: a abordagem do Círculo de Bakhtin. In: MEURER, José Luiz; BONINI, Adair; MOTTA-ROTH, Désirée (Orgs.). Gêneros: teorias, métodos, debates. São Paulo: Parábola, 2005. p. 152-183.

ROJO, Roxane. Gêneros de discurso/texto como objeto de ensino de línguas: um retorno ao trivium? In: SIGNORINI, Inês (Org.). (Re)discutir texto, gênero e discurso. São Paulo: Parábola Editorial, 2008. p. 73-108. (Investigações sobre língua[gem] situada; 2) Seqüência de: Situar a língua[gem].

SANTA CATARINA. Secretaria de Estado da Educação e do Desporto. Proposta Curricular de Santa Catarina: Educação Infantil, Ensino Fundamental e Médio: disciplinas curriculares. Florianópolis, COGEN, 1998.

SCLIAR-CABRAL, Leonor. Guia prático de alfabetização. São Paulo: Contexto, 2003.

VERÍSSIMO, Luís Fernando Veríssimo. Novas comédias da vida privada. Porto Alegre: L\&PM, 1996.

VIGOTSKI, L. S. A formação social da mente: o desenvolvimento dos processos psicológicos superiores. Organiza por Michael Cole et. al. Tradução de José Cipolla Neto, Luís Silveira Menna Barreto, Solange Castro Afeche. 7. ed. São Paulo: Martins Fontes, 2007 [1978].

. A construção do pensamento e da linguagem. Tradução de Paulo Bezerra. São Paulo: Martins Fontes, $2001[1934]$.

ZILBERMAN, Regina (Org.). Leitura em crise na escola: as alternativas do professor. 11. ed. Porto Alegre: Mercado Aberto, 1993.

\section{ANEXO - CRÔNICA LIDA E TRABALHADA NAS AULAS 15 E 19, $1^{\circ}$ ANO DO ENSINO MÉDIO}

\section{Aquilo}

- De uns tempos para cá, eu só penso naquilo.

- Eu penso naquilo desde os meus, sei lá, onze anos.

- Onze anos?

- É. E o tempo todo.

- Não. Eu, antigamente, pensava pouco naquilo. Era uma coisa que não me preocupava. Claro que a gente convivia com aquilo desde cedo. Via acontecer à nossa volta, não podia ignorar. Mas não era, assim, uma preocupação constante. Como agora.

- Pra mim sempre foi. Aliás, eu não penso em outra coisa.

- Desde criança!?

- De dia e de noite.

- E como é que você conseguia viver com isso, desde criança ?

- Mas é uma coisa natural. Acho que todo mundo é assim. Você é que é anormal, se só começou a pensar naquilo nessa idade.

- Antes eu pensava, mas hoje é uma obsessão. Fico imaginando como será. O que eu vou sentir. Como será depois.

- Você se preocupa demais. Precisa relaxar. A coisa tem que acontecer naturalmente. Se você fica ansioso é pior. Aí sim, aquilo se torna uma angústia, em vez de um prazer.

- Um prazer? Aquilo?

- Pra você não sei. Pra mim, é o maior prazer que um homem pode ter. É quando o homem chega ao paraíso.

- Bom, se você acredita nisso, então pode pensar naquilo como um prazer. Pra mim é o fim.

- Você precisa de ajuda, rapaz.

- Ajuda religiosa ? Perdi a fé há muito tempo. Da última vez que falei com um padre a respeito, só o que ele me disse foi que eu devia rezar. Rezar muito, para poder enfrentar aquilo sem medo.

- Mas você foi procurar logo um padre ? Precisa de ajuda psiquiátrica. Talvez clínica, não sei. Ter pavor 
daquilo não é saudável.

- E eu não sei ? Eu queria ser como você. Viver com a perspectiva daquilo naturalmente, até alegremente. Ir para aquilo assoviando.

- Ah, vou. Assoviando e dando pulinho. Olhe, já sei o que eu vou fazer. Vou apresentar você a uma amiga minha. Ela vai tirar todo o seu medo.

- Sei. Uma dessas transcendentalistas.

- Não é daqui mesmo. Codinome Neca. Com ela é tiro e queda. Figurativamente falando, claro.

- Hein?

- O quê?

- Do que é que nós estamos falando?

- Do que é que você está falando?

- Daquilo. Da morte.

- Ah.

- E você?

- Esquece."

Recebido em 23/o8/12. Aprovado em 16/10/12. 